within a few days patients should be given systemic steroid treatment. For the short term, high doses of prednisone $(60 \mathrm{mg}$ decreasing to maintenance doses of $15 \mathrm{mg}$ ) are effective and produce dramatic relief of the pain in the eye within 12 hours. If avascular areas are present systemic steroids, $60 \mathrm{mg} /$ day or even more, should be given until new vessels start to grow into the areas. As soon as the inflammation is suppressed dosage can be reduced rapidly. It is important not to biopsy scleral nodules or inject hydrocortisone subconjunctivally, because the sclera will not heal and perforation may be induced at the injection site.

Whereas some forms of scleritis are harmless and subside with treatment, others are severe and destructive. Necrotising scleritis is particularly sinister as it may be associated with systemic disease. Watson found in one series that $27 \%$ of patients who developed necrotising scleritis were dead within five years. ${ }^{13}$ In patients with mild rheumatoid arthritis the onset of scleritis may, in about $30 \%$ of cases, be associated with the development of "malignant" rheumatoid disease with vasculitis, and may precede it. In these patients, prompt diagnosis and systemic treatment may control both scleritis and rheumatoid arthritis.

Widespread systemic involvement, particularly of cardiovascular, respiratory, and renal systems, may be associated with scleral disease in patients with rheumatoid arthritis. ${ }^{14}$ Jayson and Jones ${ }^{10}$ found pericarditis in two of 12 patients with scleritis and rheumatoid arthritis, one of whom also had pleurisy. They noted arteritis in 10 of 14 cases of scleritis. McGavin et $a^{1}$ found ischaemic changes on electrocardiography in $60 \%$ of patients examined, and nearly $33 \%$ had Sjögren's syndrome. They also found an increase in pulmonary complications, including pleurisy, pneumonitis, pleural effusion, and rheumatoid nodules of the lung. The extra-articular features were consistently more evident in patients with rheumatoid arthritis and scleritis than in a control group with rheumatoid arthritis alone.

Not only are the extra-articular manifestations more often present where the eye is affected, but also the patients have more severe disease, more advanced radiological changes, and higher sedimentation rates and higher titres of rheumatoid factor. Ocular changes tend to occur in patients with more severe rheumatoid disease, especially vasculitis, and exacerbation occurs at times of increased activity.

The increased incidence of systemic features is reflected in a decreased life expectancy. Jones and Jayson ${ }^{15}$ found that about $36^{\circ}{ }_{0}$ had died within three years compared with about $19^{\circ}{ }_{0}$ of the control group. It is important for the rheumatologist to remember that the development of necrotising scleritis in a rheumatoid patient may shortly be followed by systemic complications.

We would like to thank the surgeons of Moorfields Eye Hospital and $\mathrm{Mr}$. I D Salt for allowing us to see and treat their patients.

\section{References}

1 McGavin, D D M, et al, British fournal of Ophthalmology, 1976, 60, 192.

2 Rooney, P J, et al, Thin sclerae: a clinical illusion. London, Heberden Society, 1974.

${ }^{3}$ McCormick, J N, Current Topics in Connective Tissue Diseases, ed P J L Holt. London, Churchill Livingstone, 1975.

4 Joysey, V C, et al, fournal of Rheumatology, 1977, 4, (suppl 3), 84.

5 McKenzie, W, A Practical Treatise on Diseases of the Eye. London, Longman, 1830

6 Van der Hoeve, J, Nederlandsch Tijdschrift voor Geneeskunde, 1931, 74, 4733.

${ }^{7}$ Verhoeff, F H, and King, M J, Archives of Ophthalmology, 1938, 20, 1013.

8 Watson, P G, and Lobascher, D, Transactions of the Ophthalmological Society of the United Kingdom, 1965, 94, 46.

${ }^{9}$ Lyne, A J, and Pitkeathley, D A, Archives of Ophthalmology, 1968, 80, 171.

10 Jayson, M I V, and Jones, D E P, Annals of Rheumatic Diseases, 1971, 30, 343.

11 Williamson, J, Transactions of the Ophthalmological Society of the United Kingdom, 1974, 94, 742 .

12 Frauenfelder, F T, and Watson, P G, British fournal of Ophthalmology, $1976,60,227$.

13 Watson, P G, Transactions of the Ophthalmological Society of the United Kingdom, 1974, 94, 65.

14 Sevel, D, American fournal of Ophthalmology, 1967, 64, 1125.

15 Jones, D E P, and Jayson, M I V, Proceedings of the Royal Society of Medicine, 1973, 66, 1161.

(Accepted 3 November 1977)

\title{
Changing pattern of drugs used for self-poisoning
}

\author{
A T PROUDFOOT, J PARK
}

British Medical fournal, 1978, 1, 90-93

\section{Summary and conclusions}

In 1967-76 the annual number of admissions to a poisoning treatment centre rose from 964 to 2134 . The proportion of admissions caused by taking barbiturate hypnotics and methaqualone fell considerably while that caused by taking benzodiazepines and tricyclic antidepressants increased. As a result the proportion of patients admitted unconscious fell from $23 \%$ to $15 \%$. The declining contributions of barbiturates and methaqualone and increased importance of tricyclic antidepressants were significant

Regional Poisoning Treatment Centre, Royal Infirmary, Edinburgh EH3 9YW

A T PROUDFOOT, BSC, FRCPED, physician

J PARK, BSC, MRCP, registrar in all grades of coma. The change in drugs taken, however, has not yet reduced the percentage of unconscious patients needing endotracheal intubation or assisted ventilation, and hypothermia remains as common. Only hypotension has become less frequent as antidepressants replace barbiturates as the main cause of drug-induced coma. The use of salicylates for self-poisoning is declining slowly, and paracetamol poisoning is now as common.

\section{Introduction}

The epidemic of self-poisoning will be remembered as one of the major medicosocial phenomena of the past 30 years. Many reports testify to its impact on the work load of general hospitals throughout Britain ${ }^{1-7}$ and in several areas the incidence continues to rise inexorably. ${ }^{15-7}$ In most cases the physical consequences of self-poisoning are minor, and the episode is more important as a manifestation of interpersonal and social strife or, less often, of psychiatric illness. The medical seriousness of other cases, however, is reflected in 1875 official deaths 
from suicide by poisoning in England and Wales in 1974 and a further 1389 poisoning deaths that did not satisfy the legal criteria of suicide but were nevertheless almost certainly the result of deliberate self-poisoning. ${ }^{8}$

Many doctors will already be aware that the pattern of drugs taken in overdosage has altered over recent years. Such changes could have important implications for the facilities required for the care of individuals who have poisoned themselves and for the eventual outcome of the episodes. We have therefore reviewed the changes in the pattern of drugs used for selfpoisoning in Edinburgh in the past decade and attempted to assess the consequences of these on morbidity from poisoning.

\section{Methods}

Over the decade 1967-76 it was our policy to admit anybody over 12 years old who was thought to have deliberately taken more than the therapeutic dose of a drug or been exposed to any toxic compound. Medical and social information about each admission for each year was coded and punched on to Hollerith cards, which were sorted and counted mechanically for analysis.

The identity and quantity of the drugs taken in overdosage was, of necessity, largely based on circumstantial and clinical evidence together with the history obtained from the patient on recovery. The presence of some drugs (particularly salicylates and paracetamol) in plasma was confirmed chemically.

The depth of coma was graded according to the criteria of Matthew and Lawson. Patients in coma grades 2, 3, and 4 are unconscious since none will respond to a verbal command but react maximally, minimally, or not at all to painful stimuli. Hypotension was considered to be present when the systolic blood pressure fell below $80 \mathrm{~mm} \mathrm{Hg}$ in patients aged less than 40 years and below $90 \mathrm{~mm} \mathrm{Hg}$ in those over that age. Hypothermia was defined as a rectal temperature of less than $35^{\circ} \mathrm{C}$.

Changes in the morbidity from poisoning have been assessed by comparing percentages for the two consecutive five-year periods. Since such an arbitrary division might introduce artefacts, however, trends in the raw data for the 10 years have been tested by Cox's test for trends in contingency tables. ${ }^{10}$

\section{Results}

The annual number of admissions rose from 964 in 1967 to 2134 in 1976 (table I), with a maximal annual rate of increase of $21 \%$ between 1970 and 1971.

TABLE I-Annual number of admissions and number and percentage unconscious

\begin{tabular}{c|c|c|c}
\hline \multirow{2}{*}{ Year } & \multirow{2}{*}{ No of admissions } & \multicolumn{2}{|c}{ Unconscious patients } \\
\cline { 3 - 4 } & & No & $\%$ \\
\hline 1967 & 964 & 226 & 23 \\
1968 & 1067 & 222 & 21 \\
1969 & 1173 & 224 & 19 \\
1970 & 1342 & 255 & 19 \\
1971 & 1628 & 248 & 15 \\
1972 & 1766 & 322 & 18 \\
1973 & 1765 & 245 & 14 \\
1974 & 1744 & 263 & 14 \\
1975 & 1895 & 324 & 15 \\
1976 & 2134 & & \\
\hline
\end{tabular}

\section{CHANGES IN PATTERN OF DRUGS TAKEN}

Benzodiazepines, barbiturates, tricyclic antidepressants, salicylates, and paracetamol are the most common drugs encountered, and the figure shows the percentage of self-poisonings accounted for by each of these drugs, and also methaqualone (usually Mandrax), from 1967 to 1976. The proportion of patients who had taken barbiturate hypnotics declined from $30 \%$ to $15 \%$ over the decade, while those who had taken benzodiazepines (mainly diazepam and to a lesser extent chlordiazepoxide and nitrazepam) so far increased that this is now by far the commonest group of drugs taken in overdosage $(40 \%$ of admissions in 1976). The use of tricyclic antidepressants has also
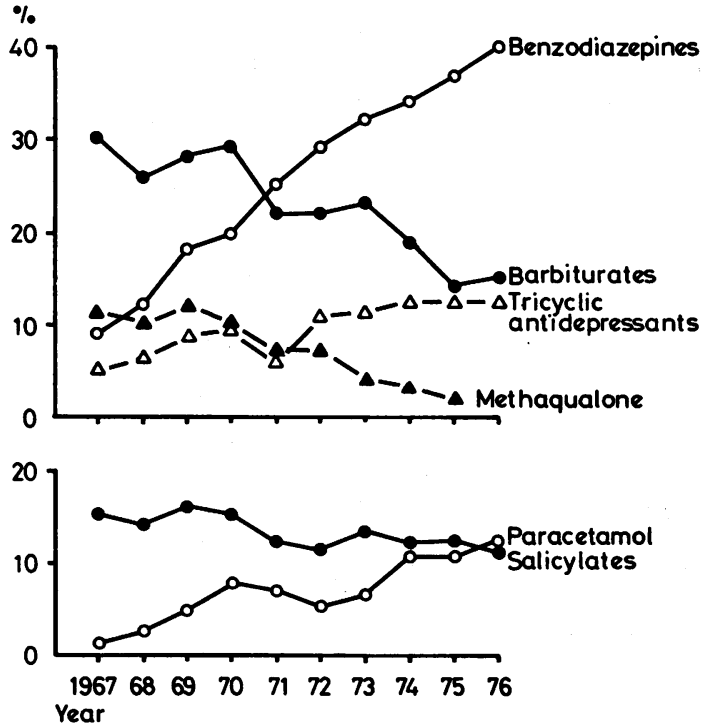

Proportions of all poisoning admissions involving barbiturates, benzodiazepines, methaqualone, tricyclic antidepressants, salicylates and paracetamol annually 1967-76.

been increasing, though relatively slowly, while methaqualone intoxication has become less common.

Salicylates and paracetamol are the most frequently taken drugs that have important toxic effects without usually impairing consciousness. The proportion of admissions involving patients who had taken salicylates has shown a slow but significant decline over the years while paracetamol poisoning, which was uncommon in 1967, is now as frequent as salicylate poisoning.

\section{CONSEQUENCES OF THE CHANGING PATTERN}

The main consequence of the changing pattern of drugs taken in overdosage over the decade is a reduction in the proportion of patients admitted unconscious from $23 \%$ to $15 \%$ (table I). This trend is highly significant.

The change in distribution of unconscious patients in coma grades 2,3 , and 4 between the two five-year periods is shown in table II. The percentage admitted in the least serious grade of coma (grade 2) has increased at the expense of that in grade $3\left(\chi^{2}=18.05 ; \mathrm{DF}=2\right.$; $P<0.0005$ ), while the proportion of patients admitted in the deepest coma (grade 4) has not altered significantly.

TABLE II-Changes in proportions of unconscious patients in different coma grades in two five-year periods

\begin{tabular}{|c|c|c|c|}
\hline \multirow{2}{*}{$\begin{array}{l}\text { Coma } \\
\text { grade }\end{array}$} & \multicolumn{2}{|c|}{ Percentage of all patients in coma } & \multirow{2}{*}{$\underset{(\%)}{\text { Change }}$} \\
\hline & $1967-71$ & $1972-6$ & \\
\hline $\begin{array}{l}2 \\
3 \\
4\end{array}$ & $\begin{array}{l}43.7 \\
36.4 \\
19.8\end{array}$ & $\begin{array}{l}49 \cdot 7 \\
28 \cdot 7 \\
21 \cdot 6\end{array}$ & $\begin{array}{r}+6.0 \\
+7.7 \\
+1.8\end{array}$ \\
\hline
\end{tabular}

The relative contributions of barbiturate hypnotics, methaqualone, and tricyclic antidepressants to each of the three coma grades are compared similarly for the five-year periods in table III. Barbiturates and methaqualone contributed less to all grades of coma in the second five-year period; but whereas the major reduction in methaqualone is in the less severe coma, the reduction for barbiturates has been greatest in the most profound comas. In contrast, tricyclic antidepressants significantly increased their contributions to all grades of coma.

The severity of poisoning in unconscious patients is also reflected in the frequency of endotracheal intubation and assisted ventilation and of hypotension and hypothermia. There has been little change in the need for endotracheal intubation or in the incidence of hypothermia (which has only been coded routinely since 1971), but hypotension 
appears to have become less common (table IV). These trends are statistically significant. Assisted ventilation of unconscious patients rose from $4 \%$ in 1967 to $13 \%$ in 1971 but has fallen again to earlier levels. Analysis of the trend over the decade showed no significant change.

TABLE III-Changes in relative contributions of barbiturates, methaqualone, and tricyclic antidepressants to different grades of coma

\begin{tabular}{|c|c|c|c|c|}
\hline \multirow[t]{2}{*}{ Drug group } & \multirow{2}{*}{$\begin{array}{l}\text { Coma } \\
\text { grade }\end{array}$} & \multicolumn{2}{|c|}{$\begin{array}{l}\text { Percentage of all } \\
\text { patients in each } \\
\text { coma grade }\end{array}$} & \multirow[t]{2}{*}{$\underset{(\%)}{\text { Change }}$} \\
\hline & & $1967-71$ & $1972-6$ & \\
\hline Barbiturate hypnotics & $\begin{array}{l}2 \\
3 \\
4\end{array}$ & $\begin{array}{l}32 \cdot 3 \\
41 \cdot 3 \\
59 \cdot 5\end{array}$ & $\begin{array}{l}24 \cdot 8 \\
32 \cdot 3 \\
45 \cdot 1\end{array}$ & $\begin{array}{r}-7.5 \\
-9 \cdot 0 \\
-14.4\end{array}$ \\
\hline Methaqualone & $\begin{array}{l}2 \\
3 \\
4\end{array}$ & $\begin{array}{r}20 \cdot 0 \\
17 \cdot 1 \\
7 \cdot 3\end{array}$ & $\begin{array}{l}5 \cdot 0 \\
7 \cdot 6 \\
3 \cdot 2\end{array}$ & $\begin{array}{r}-15.0 \\
-9.5 \\
-4.1\end{array}$ \\
\hline Tricyclic antidepressants & $\begin{array}{l}2 \\
3 \\
4\end{array}$ & $\begin{array}{r}13.3 \\
11.3 \\
3.9\end{array}$ & $\begin{array}{l}27.2 \\
27.5 \\
15.8\end{array}$ & $\begin{array}{l}+13.9 \\
+16.2 \\
+11.9\end{array}$ \\
\hline
\end{tabular}

TABLE IV-Indices of severity of poisoning in unconscious patients

\begin{tabular}{c|c|c|c|c}
\hline Year & $\begin{array}{c}\text { Endotracheal } \\
\text { intubation } \\
(\%)\end{array}$ & $\begin{array}{c}\text { Assisted } \\
\text { ventilation } \\
(\%)\end{array}$ & $\begin{array}{c}\text { Hypotension } \\
(\%)\end{array}$ & $\begin{array}{c}\text { Hypothermia } \\
(\%)\end{array}$ \\
\hline 1967 & 22 & 4 & 30 & $*$ \\
1968 & 24 & 6 & 38 & $*$ \\
1969 & 22 & 7 & 28 & $*$ \\
1970 & 32 & 11 & 28 & 7 \\
1971 & 26 & 13 & 16 & 7 \\
1972 & 30 & 11 & 19 & 5 \\
1973 & 17 & 7 & 27 & 8 \\
1974 & 27 & 8 & 16 & 5 \\
1976 & 26 & 5 & 16 & 6 \\
\hline
\end{tabular}

*Data incomplete.

Table $\mathrm{V}$ shows the annual numbers of patients needing treatment over and above gastric lavage for salicylate and paracetamol poisoning - usually forced alkaline diuresis (for salicylates) or intravenous administration of cysteamine, methionine, or other SH-donors (for paracetamol)

TABLE V-Annual numbers of patients needing active treatment for salicylate and paracetamol poisoning. Percentages of all poisonings caused by salicylate or paracetamol in parentheses

\begin{tabular}{c|c|c}
\hline & \multicolumn{2}{|c}{ No requiring active treatment } \\
\cline { 2 - 3 } Year & Salicylate & Paracetamol \\
\hline 1967 & $34(24)$ & $*$ \\
1968 & $34(19)$ & $*$ \\
1969 & $35(19)$ & $*$ \\
1970 & $28(14)$ & $*$ \\
1971 & $56(28)$ & $*$ \\
1972 & $50(18)$ & $7(7)$ \\
1973 & $49(22)$ & $26(15)$ \\
1974 & $71(31)$ & $22(12)$ \\
1975 & $65(28)$ & $19(8)$ \\
\hline
\end{tabular}

*Specific treatment not available.

\section{Discussion}

The number of self-poisonings in adults continues to increase and to be a burden on the National Health Service. There is no evidence of a substantial decrease or levelling-off to suggest that a "saturation point" has been reached (table I). Furthermore, the incidence may be even greater because benzodiazepines, which rarely cause serious or prolonged central nervous system depression, account for a larger proportion of the drugs ingested. Fewer patients may therefore be referred to hospital. A survey of Edinburgh general practices in 1970 showed that about one-third of all adult poisonings were managed at home, ${ }^{11}$ and this proportion is probably greater in regions lacking our open-door policy for individuals at little physical risk from a self-poisoning episode.

The decade 1967-76 has seen much of the decline of barbiturates and methaqualone and the ascendency of benzodiazepines for self-poisoning (see figure). The rate of increase in poisoning with tricyclic antidepressants has been comparatively slow. The net result of substituting benzodiazepines for barbiturates and methaqualone has been a smaller proportion of patients admitted unconscious to hospital, but the number of admissions each year has increased so rapidly that 98 more unconscious patients were managed in 1976 than in 1967 (table I).

The proportion of unconscious patients in deepest coma (grade 4) has not altered significantly while that in the least serious grade of coma (grade 2) has increased at the expense of patients in the intermediate grade (table II). This may account for the lack of change in the incidence of endotracheal intubation, assisted ventilation, and hypothermia (table IV) since these are most frequent in grade 4 coma. ${ }^{12}$

The overall decrease in the use of barbiturate hypnotics (see figure) has been paralleled by reductions in the contributions of this group of drugs to grade 2 and grade 3 coma, and even more to grade 4 coma. In contrast, the major impact of the diminished use of methaqualone has been on the proportion of patients in less severe coma (grades 2 and 3) (table III). Clearly, tricyclic antidepressants are largely replacing barbiturate hypnotics and methaqualone as causes of deep coma (grades 3 and 4 ) and to a lesser extent grade 2 coma, though in this grade benzodiazepines, particularly in combination with ethanol, may be making an important contribution. The less frequent occurrence of hypotension in unconscious patients (table IV) may be explained by the changing contributions of the major groups of drugs since tricyclic antidepressants seem less likely to cause this complication than barbiturates. ${ }^{13}$ If this trend in drugs continues we would also expect hypothermia to become a less frequent problem. Equally, we can expect potentially fatal convulsions and cardiac dysrhythmias to become more common and delirium and hallucinations to delay recovery more often.

It is surprising that the incidence of tricyclic antidepressant poisoning has not risen faster. This may be due to awareness of the special hazards of these drugs in overdosage, but more probably it is because more patients are being treated inappropriately with depressant minor tranquillisers.

Though the incidence of salicylate poisoning has declined slowly over the decade, analysis shows a slight trend towards treating a higher proportion with forced alkaline diuresis. The exact reason for this is not clear, but we believe it to be due to a reduced threshold for treatment rather than to an increased occurrence of severe poisoning.

Acute overdosage with paracetamol has become increasingly common, partly because doctors advise patients to take this drug rather than aspirin when a simple analgesic is needed and partly owing to the widespread prescribing of Distalgesic (paracetamol and dextropropoxyphene hydrochloride). ${ }^{14}$ When it became apparent that paracetamol overdosage could cause fatal hepatic necrosis ${ }^{15}$ there was concern that the switch from aspirin to paracetamol would lead to an increased death rate from poisoning. This fear has not been realised, ${ }^{16}$ and only a relatively small proportion of patients with paracetamol poisoning need treatment to prevent hepatic damage (table V).

In conclusion, the changes in the pattern of major drugs used for self-poisoning have been associated with a reduced morbidity as seen in patients admitted to hospital. Nevertheless, the number of self-poisonings rises annually to such an extent that over the next few years medical units can expect to have to treat as many if not more people who are physically ill from overdosage.

We are grateful to Dr Henry Matthew and Dr L F Prescott for permission to report on patients under their care, to colleagues and 
secretaries who assisted in the collection and coding of information, and to Mrs A Avery who carried out the statistical analyses.

\section{References}

1 Murray, J C, et al, Scottish Medical fournal, 1974, 19, 279.

2 Morgan, H G, et al, British fournal of Psychiatry, 1975, 127, 564. 3 Ghodse, A H, British Fournal of Preventive and Social Medicine, 1976, 30,

4 Brodribb, H S, Update, 1976, June, 1399.

5 Matthew, H, Medicine (London), 1975, second series, No 5, p 214.

${ }^{6}$ Bancroft, J H J, British Fournal of Preventive and Social Medicine, 1975, 29, 170 .
7 Jones, D I R, British Medical fournal, 1977, 1, 28.

8 Office of Population Censuses and Surveys, Mortality Statistics: Accidents and Violence, 1974, series DH4 No 1, p vi. London, HMSO, 1976.

Matthew, H, and Lawson, A A H, Treatment of Common Acute Poisonings, 3rd edn. London, Churchill Livingstone, 1975.

10 Cox, D R, Analysis of Binary Data. London, Methuen, 1970.

11 Kennedy, P, British Medical fournal, 1972, 4, 255.

12 Proudfoot, A T, and Park, J, unpublished observations.

13 Thorstrand, C, Acta Medica Scandinavica, 1974, 195, 505.

14 Whittington, R M, British Medical fournal, 1977, 2, 172.

${ }_{15}$ Davidson, D G D, and Eastham, W N, British Medical fournal, 1966, 2, 497.

16 Volans, G N, fournal of International Medical Research, 1976, 4, suppl 4, 7.

(Accepted 10 November 1977)

\section{Letter from . . . Victoria}

\section{Funding of medical care}

\section{JOHN KNIGHT}

British Medical fournal, 1978, 1, 93-94

The past few years have seen many changes in the funding of medical care in Australia. In July 1975 the Labour Government introduced Medibank. Medibank was a logical step beyond the multitude of health insurance organisations that had up till then provided for the medical costs of Australians. Medibank, which was in effect a government insurance scheme covering everybody, was introduced in the teeth of the Opposition's opposition. The Opposition controlled the Senate and refused to pass the legislation that would have funded Medibank by an extra levy on income tax. Nothing daunted, the Government funded Medibank from consolidated revenue. So the new universal scheme was introduced as a "free" service.

In November 1975 the Governor-General, relying on a literal reading of the constitution and paying no attention to precedent, dismissed the Labour Government while it still had a majority in the House of Representatives. What precipitated this action was the refusal of the Opposition to allow the supply bills to be debated. This meant that the Government was soon to be out of funds.

The Liberal (in English terms Conservative) party won the ensuing election and set about cutting government spending. Among the many casualties was the "free" Medibank. In October 1976 the idea of a single universal insurance scheme was discarded. At the same time a levy (anathema to the Liberals when in opposition) was introduced to pay for Medibank. This levy was set, in the name of freedom of choice, at a higher level than the various benefit societies were to charge for basic hospital and medical cover. Moreover, the contributions for health care insurance were no longer to be income-tax deductions. The whole cost of his medical and hospital insurance,

Grey Street Anaesthetic Group, East Melbourne, Victoria, Australia JOHN KNIGHT, FFARCS, specialist anaesthetist which he is now compelled to have, was to be borne directly by John Citizen. All trace of government subsidy was removed for the average citizen, only pensioners and the very poor being excused from the levy.

At the same time new regulations were introduced about direct payment to the doctor from Medibank. Under Medibank I (July 1975 to October 1976) the patient could sign a voucher in his doctor's surgery and the doctor could then claim the rebate, and only the rebate, from Medibank. Some bad apples in the medical applecart took advantage of this form of open cheque and charged for services not rendered. One such was recently prosecuted for having falsely claimed about $\$ 250000$. He was convicted. Later he was struck from the register by the medical board of his State. About a dozen doctors have been prosecuted for falsely claiming large amounts. Some indicted themselves by claiming for several prolonged consultations (over 45 minutes) a day. Unfortunately they must have had days longer than 24 hours to fit in all the consultations. The Medibank computers found these very long days difficult to believe.

Now the patient may still sign a voucher for direct payment of the doctor, but the patient has to be given a copy of the voucher so that he knows what service was rendered-or perhaps so that the Medibank checkers can call to see that the carbon copy corresponds with the original. My own view is the latter. Mercifully, the vouchers are "no carbon required" paper.

\section{Malpractice in pathology services}

Malpractice was also noticeable in the pathology services. In the Australian system there are private pathology services in parallel with the hospital pathology services. The private services provide for most of the population, as the hospital services only provide for their own inpatients and outpatients. The private services are owned either by the pathologist or by companies that employ pathologists. The fees set by the Labour Government were those prevailing before Medibank. At much the same time as Medibank was introduced pathology services were going over to automation. To use the machines most efficiently many tests on each specimen were needed. So some 